\title{
$\alpha$-Aminoisobutyric acid-containing amphipathic helical peptide-cyclic RGD conjugation as a potential drug delivery system for microRNA replacement therapy in vitro
}

Kohei Taniguchi, ${ }^{1,2 *}$ Shun-ichi Wada, ${ }^{3}$ Yuko Ito, ${ }^{1}$ Junsuke Hayashi, ${ }^{3}$ Yosuke Inomata ${ }^{1}$, Sang-Woong Lee ${ }^{1}$, Tomohito Tanaka, ${ }^{2}$ Kazumasa Komura, ${ }^{2}$ Yukihiro Akao, ${ }^{4}$ Hidehito Urata $^{3}$, and Kazuhisa Uchiyama ${ }^{1}$

${ }^{1}$ Department of General and Gastroenterological Surgery, Osaka Medical College, 2-7 Daigaku-machi, Takatsuki, Osaka 569-8686, Japan

2 Translational Research Program, Osaka Medical College, 2-7 Daigaku-machi, Takatsuki, Osaka 569-8686, Japan

${ }^{3}$ Department of Bioorganic Chemistry, Osaka University of Pharmaceutical Sciences, 420-1 Nasahara, Takatsuki, Osaka 569-1094, Japan

${ }^{4}$ United Graduate School of Drug Discovery and Medical Information Sciences, Gifu University, 1-1 Yanagido, Gifu 501-1193, Japan 
Table S1. Detailed information from previous reports on the association between MIR145 and FSCN1 (from miRTarBase).

\begin{tabular}{|c|c|c|c|c|c|}
\hline $\begin{array}{c}\text { Reference } \\
\text { Author, (year) }\end{array}$ & PMID & Associated disease & $\begin{array}{c}\text { Method for } \\
\text { experimental validation }\end{array}$ & Tissue, cell lines & Note \\
\hline Chiyomaru et al. (2010) & 20160723 & Bladder cancer & $\begin{array}{l}\text { Luciferase reporter assay, } \\
\text { qRT-PCR, Western blot }\end{array}$ & $\begin{array}{l}\text { BOY, T24, KK47 } \\
\text { Human bladder tissue }\end{array}$ & $\begin{array}{l}\text { Oligo-microarray analysis showed } \\
\text { FSCN1 was most down-regulated gene } \\
\text { in MIR145-treated cells }\end{array}$ \\
\hline Wu et al. (2011) & 21218087 & $\begin{array}{l}\text { Esophageal squamous } \\
\text { cell carcinoma }\end{array}$ & Western blot & KYSE150, KYSE180 & $\begin{array}{l}\text { Down-regulation of FSCN1 was not } \\
\text { detected in MIR145-treated cells }\end{array}$ \\
\hline Fuse et al. (2011) & 21258769 & Prostate cancer & $\begin{array}{l}\text { Luciferase reporter assay, } \\
\text { qRT-PCR, Western blot }\end{array}$ & $\begin{array}{c}\text { PC3, DU145 } \\
\text { Human Prostate tissue }\end{array}$ & $\begin{array}{l}\text { Oligo-microarray analysis showed } \\
\text { FSCN1 was most down-regulated gene } \\
\text { in MIR145-treated cells }\end{array}$ \\
\hline Kano et al. (2010) & 21351259 & $\begin{array}{l}\text { Esophageal squamous } \\
\text { cell carcinoma }\end{array}$ & $\begin{array}{l}\text { Luciferase reporter assay, } \\
\text { qRT-PCR, Western blot }\end{array}$ & $\begin{array}{l}\text { TE2, TE3, TE12, TE13 } \\
\text { Human Esophageal tissue }\end{array}$ & $\begin{array}{l}\text { Oligo-microarray analysis showed } \\
\text { FSCN1 was most down-regulated gene } \\
\text { in MIR145-treated cells }\end{array}$ \\
\hline Adammek et al. (2013) & 23312222 & Endometriosis & $\begin{array}{l}\text { Luciferase reporter assay, } \\
\text { qRT-PCR, Western blot }\end{array}$ & $\begin{array}{c}12 \mathrm{Z}, \\
\text { primary eutopic endometrial cells }\end{array}$ & $\begin{array}{l}\text { Target sites were calculated using } \\
\text { the miRanda algorithm according to } \\
\text { the microRNA.org database }\end{array}$ \\
\hline Feng et al. (2014) & 24642628 & Colorectal cancer & $\begin{array}{l}\text { Luciferase reporter assay, } \\
\text { qRT-PCR, Western blot, IHC }\end{array}$ & $\begin{array}{c}\text { FHC, NCM460, SW480, SW620, } \\
\text { HT29, LoVo, LS174T } \\
\text { Human Colorectal tissue }\end{array}$ & $\begin{array}{l}F S C N 1 \text { was down-regulated by } \\
\text { overexpression of MIR145 in vivo }\end{array}$ \\
\hline Li et al. (2015) & 25816323 & $\begin{array}{l}\text { Nasopharyngeal } \\
\text { carcinoma }\end{array}$ & $\begin{array}{l}\text { Luciferase reporter assay, } \\
\text { qRT-PCR, Western blot }\end{array}$ & $\begin{array}{c}\text { NP69, CNE-1, CNE-2 } \\
\text { C666-1, SUNE-1, HNE-1, HONE-1 } \\
\text { Human Nasopharyngeal tissue }\end{array}$ & $\begin{array}{l}\text { CNE-1 and SUNE-1cells } \\
\text { were mainly used }\end{array}$ \\
\hline Chen et al. (2015) & 26010149 & Gastric cancer & $\begin{array}{l}\text { Luciferase reporter assay, } \\
\text { qRT-PCR, Western blot, } \\
\text { inhibitor }\end{array}$ & $\begin{array}{l}\text { SGC-7901, MGC-803 } \\
\text { Human Gastric tissue }\end{array}$ & $\begin{array}{l}\text { Strong relation between } \\
\text { MIR145 and FSCN1 was observed } \\
\text { in infiltrative type }\end{array}$ \\
\hline Wang et al. (2015) & 26173501 & $\begin{array}{l}\text { Hepatocelluar } \\
\text { carcinoma }\end{array}$ & $\begin{array}{l}\text { Luciferase reporter assay, } \\
\text { qRT-PCR, Western blot, }\end{array}$ & $\begin{array}{l}\text { LO2, HuH7, 97-L, 97-H, } \\
\text { SMMC7721, HepG2, } \\
\text { Human liver tissue }\end{array}$ & HepG2 cell was mainly used \\
\hline Zhang et al. (2015) & 26309531 & $\begin{array}{l}\text { Non-small cell } \\
\text { lung cancer }\end{array}$ & $\begin{array}{l}\text { qRT-PCR, Western blot } \\
\text { inhibitor }\end{array}$ & $\begin{array}{l}\text { A549, H460, H1299 } \\
\text { Human lung tissue }\end{array}$ & A549 cell was mainly used \\
\hline Xue et al. (2016) & 26647829 & Gastric cancer & $\begin{array}{l}\text { Luciferase reporter assay, } \\
\text { qRT-PCR, Western blot, } \\
\text { inhibitor }\end{array}$ & $\begin{array}{c}\text { GES1, BGC823, SGC7901, SNU5, } \\
\text { HGC27, AGS }\end{array}$ & AGS cell was mainly used \\
\hline Zhao et al. (2016) & 27508031 & Breast cancer & Western blot & $\begin{array}{l}\text { MDA-MB-231, MDA-MB-486, } \\
\text { Bcap-37, HCC-1937 }\end{array}$ & $\begin{array}{l}\text { Bcap- } 37 \text { and HCC- } 1937 \text { cells } \\
\text { were mainly used }\end{array}$ \\
\hline
\end{tabular}

